\title{
Fragmented Foreign Language Learning Among Higher Vocational College Students: Current Situation, Dilemma and Countermeasures
}

\author{
Xin Wang* \\ Zhengzhou Railway Vocational and Technical College \\ Zhengzhou, China
}

\begin{abstract}
With the hyper-development of the mobile Internet, the fragmented, Internet+-based model of foreign language learning has become a general trend and an important learning method for college students. On the basis of the questionnaire survey, this paper makes a detailed understanding of the characteristics of fragmented foreign language learning among college students, and summarizes its advantages, influencing factors and defects. After that, the paper makes an in-depth analysis of fragmented foreign language learning method from the perspectives of cognitive psychology, constructivism and connectivism theory, and puts forward suggestions on improving fragmented foreign language learning strategies and the efficiency of foreign language teaching.
\end{abstract}

Keywords-Internet+; fragmented learning; foreign-language learning; coping strategies

\section{INTRODUCTION}

Due to the hyper-development of the mobile Internet, the fragmented model of foreign-language learning, based on Internet + , has become both a general trend and an important method of learning for many office workers and college students. Supported by information technology, tablet and smartphone applications, and other learning tools, students can obtain online learning resources and experiences anytime and anywhere. The Internet fully satisfies their need for personalized and diversified learning by overcoming the limitations previously imposed by time, space, content, and tools; as a result, the learning process has become more proactive and flexible. This widespread method of learning has significantly impacted the way in which college students approach and implement foreign-language learning, leading to profound changes.

According to the report released by the Horizon Survey, nearly 100 percent of Chinese college students surf the Internet, and about $70 \%$ of them are mainly engaged in "acquiring information and learning" on the mobile Internet. In addition, the 2019 CMNet Autumn Report also shows that the number of users of learning software, such as Zhihu, Kaoyan, Xuexitong and WeChat reading, has reached more than 15 million. Under the surging tide of fragmented learning, how do contemporary college students, especially high vocational college students, view fragmented foreign language learning? How about the learning experience? What are the puzzles and challenges? The research and discussion of these questions will help us understand the behavioral characteristics and habits of fragmented foreign language learning among higher vocational college students, explore the relationship between foreign language learning effect and fragmented foreign language learning, and clarify various factors affecting fragmented foreign language learning effect. On this basis, an effective foreign language learning and teaching model can be established to improve the foreign language level of higher vocational college students.

\section{SURVEY OF FRAGMENTED FOREIGN LANGUAGE} LEARNING AMONG HIGHER VOCATIONAL COLLEGE STUDENTS

Driven by these questions, this study designed a questionnaire consisting of 16 items in 4 dimensions. A total of 95 questionnaires were distributed and 94 valid questionnaires were recovered, among which, 25 were male students and 69 were female students. Then, SPSS19.0 statistical software was used for statistical processing and analysis, and the actual frequency and relative number were used to describe the survey results. The chi-square test or Fisher's exact probability test was used for comparison between groups, with gender and English final test scores

The survey results show that the respondents agree that English learning is very important and they all have a clear learning purpose. However, students with good grades mainly think that the traditional English teaching environment has no situational and interactive features, while students with poor grades mainly lack interest in learning a foreign language and have no desire to learn English. As a highly personalized learning method, fragmented learning is generally welcomed by students, many of whom have put it into practice. In practice, most students spend less than 2 hours on fragmented learning every day, mainly for memorizing words and practicing oral English. The classroom is the first choice for students to conduct fragmented learning mainly with learning Apps. On the whole, students' purpose of fragmented learning is clear and practical, but traditional classroom and paper textbooks are still the main ways for college students to learn English. Fragmented learning is only an auxiliary and extension of classroom learning. It is the independent behavior of students after the completion of traditional classroom learning, and also an important choice for students who have 
the ability to learn to improve themselves.

Although fragmented learning is popular, its learning content is disorganized and unsystematic, the learning process is susceptible to external factors, and the students' lack of selfmanagement ability is also prominent, coupled with the lack of teachers' participation and guidance, resulting in generally poor learning effects. From the examination result, that is, there is no positive correlation between learning engagement and learning achievement.

\section{THEORETICAL ANALYSIS OF FRAGMENTED FOREIGN LANGUAGE LEARNING}

Fragmented learning is a revolution of autonomous learning brought about by mobile Internet, which is of great significance to reform the traditional foreign language learning and teaching mode. Therefore, it is necessary to discuss and analyze it from a theoretical perspective. Finally, complete content and organizational editing before formatting. Please take note of the following items when proofreading spelling and grammar:

\section{A. Fragmented Learning from the Perspective of Cognitive Psychology}

Learning is a complex thinking activity, and different learning methods involve different thinking activities. In the 1950s, Benjamin Bloom, a famous American educational psychologist, divided human thinking into six levels in his book Classification of Educational Goals: Cognitive Domain: memorization-memory, knowledge, recall important nouns, facts, methods, rules, principles; understanding-understand the meaning of important nouns and concepts and interpret them; application-apply the knowledge concepts, methods, steps and principles to different situations; analysis-decompose and recombine some information of knowledge, components, elements, relationships, organizational principles, etc., and clarify the relationships between them; synthesis-rearrange or combine elements of knowledge into an organized whole, or present relationships between them, thereby creating new ideas and predicting possible outcomes; evaluation-evaluate or compare knowledge information according to a rule.

These mental activities, or cognitive skills, are arranged in order from simple to complex. The simplest cognitive skill is the memory of knowledge. The most complex cognitive skill is the judgment of the value of ideas. Based on Bloom's cognitive theory, American scholars Ference Marton and Roger Saljo proposed the concepts of surface learning and deep learning by analyzing the results of students' reading experiment in 1976. They believed that the cognitive level of surface learning was limited to memorization and understanding. Learners passively accept the learning contents and simply memorize and copy the knowledge and the contents taught by teachers, but they do not fully understand what they have learned. Such learning mode makes students forget what they have learned soon after class. The cognitive level of deep learning corresponds to the last four levels. It means that on the basis of understanding, learners can critically learn new ideas and facts, integrate them into the original cognitive structure to establish connections, and transfer existing knowledge to new situations to make decisions and solve problems.
The two theories come together to form a clear model of cognitive ability, as shown below:

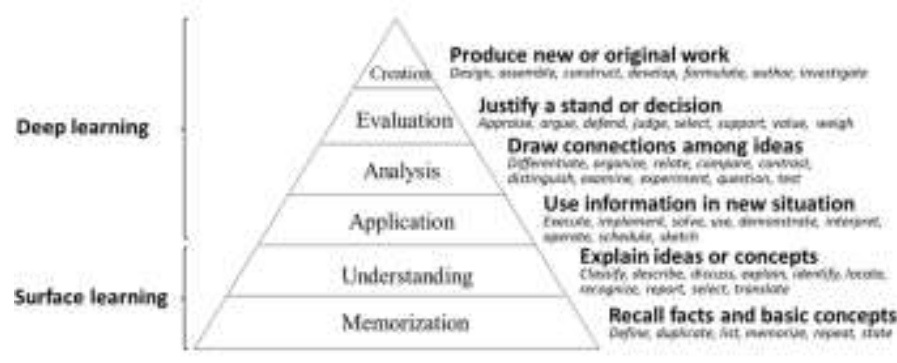

Fig. 1. Cognitive Ability Model

Based on this model, we find in the survey that many learners tend to only "watch the teaching video" when they are engaged in fragmented learning, lacking necessary pauses, proper recording and in-depth thinking. Their brain activity only remains in the surface learning stage, lacking the analysis and application of knowledge, not to mention face-to-face communication and interaction. As a result, a large number of learning resources have not been utilized by learners, failing to play their values and roles. In addition, although there are a large number of fragmented learning resources in various forms, they are not integrated with learners' learning needs. Learners are faced with some single, independent, illogical, huge and unrelated fragmented learning resources, which will undoubtedly bring about serious cognitive load.

\section{B. Fragmented Learning from the Perspective of Constructivism and Connectivism}

So how to avoid the phenomenon that learners invest time and energy in fragmented learning and feel fulfilled, but the learning effect cannot be measured? This needs us to seek the answer from the constructivism, connectionism and the independent learning theory.

To be specific, according to constructivism, learning is not to passively receive information stimulation, but to actively construct meaning. It is to select and process external information according to one's own experience and background, so as to obtain one's own meaning. The external information itself has no meaning. The meaning is constructed by learners through the repeated and two-way interaction between the old and the new knowledge experience. The acquisition of learning meaning means that each learner, on the basis of his own original knowledge and experience, reunderstands and codes new information and constructs his own understanding. In this process, learners' original knowledge experience will be adjusted and changed with the introduction of new knowledge experience. This theory clearly tells us that effective learning requires learners to exert their subjective initiative, purposefully and selectively discard external information, integrate external information into the existing knowledge structure through relation, thinking, communication and discussion, to form a new cognitive system.

According to connectivism, learning is mainly a continuous process of forming a knowledge network. However, in the era of network learning, the amount of knowledge has exploded, 
and learners always acquire much more knowledge than they can handle. So it's important to learn to choose. On this basis, fragmented information is systematically constructed and integrated according to learners' cognitive needs, so as to help them form a systematic knowledge framework and ultimately accumulate personal knowledge and experience.

It follows that both constructivism and connectivism emphasize "focusing on individual needs" and give full play to learners' subjective initiative of "self-reliance, self-discipline and self-action" to select, process and manage knowledge purposefully. At the same time, the contents of fragmented learning must also be related to the contents and goals of formal learning, otherwise the short-term freshness and surface learning gains cannot be truly embedded in the learners' existing knowledge structure and bring long-term learning benefits to them.

\section{SUGGESTIONS ON IMPROVING FRAGMENTED FOREIGN LANGUAGE LEARNING EFFECT}

As such, we give the following suggestions on improvement of fragmented foreign language learning effect among higher vocational college students:

\section{A. Approach Their Studies with Specific Aims, and Specify and Extend Their Learning Aims to Form a Set of Quantitative, Executable and Evaluable Learning Plans.}

Any effective learning has a basic process which can be roughly divided into 8 stages: goal setting $\rightarrow$ data acquisition $\rightarrow$ data selecting $\rightarrow$ cognition acquisition $\rightarrow$ cognition digestion $\rightarrow$ cognition solidification $\rightarrow$ model establishment $\rightarrow$ model expansion. The above learning process is based on learning aims, so it should be the first task to help students set up specific learning aims.

Generally speaking, higher vocational college students' short-term aim of foreign language learning is to pass the academic examination and obtain credits, and their mediumterm aim is to pass the national CET-4 and CET-6 exams and obtain certificates of relevant grades. While due to their different professional and personal development choices, their long-term aims may be different. For example, it may be necessary for them to pass the IELTS exam to study abroad, to pass the upgrade from junior exam for further domestic education, or to pass the on-boarding exam for their occupation, and so on. These three stages of learning aims progressively go forward one by one in sequence, and they are both common and individual in nature. Therefore, teachers should make every effort to find the maximum common divisor of students at each stage, to incorporate their spontaneous fragmented learning in spare time into the big aims of English teaching; help them formulate learning plans, so that learners may have a clear understanding of knowledge structure and ability aims of each stage; give students targeted guidance in good time, so that they can obtain concrete and practical gains.

\section{B. Systematically Reorganize the Fragmented Resources Based on Theories of Connectionism and ZPD}

Due to restricted learning value and effect produced from a single and isolated fragmented learning resource, it is necessary to connect fragmented resources according to certain logical relations, organizational methods and organizational strategies in an orderly manner by means of information technology to form systematic and structured learning resources, so that learners may get their fragmented inputs systematically accumulated. At the same time, according to Vygotsky's ZPD theory, difficulty of learning resources should be consistent with the cognitive level of learners. The content arrangement among different stages and modules should also accord with the learners' ability improvement curve, so that it can arouse learners' enthusiasm and exert their potential, and improve their sense of self-efficacy and sense of achievement.

In addition, teachers may also provide various learning resources of diverse forms in combination with pictures, audios and videos to arouse learners' multiple sensory organs and stimulate their learning interest. As far as English teaching in higher vocational college is concerned, teachers can make full use of mobile phone apps such as Mosoink, Unipus and ICVE to carry out electronic transformation and secondary development of existing teaching materials to provide supporting resources for fragmented learning, and give students synchronous or asynchronous guidance in online learning platform, WeChat and QQ groups, etc. to improve their learning efficiency. Conversely, students can also communicate and solve problems through cooperation on the platform to form a network learning community.

\section{Cultivate Students' Self-management Ability to Lay the Foundation for Lifelong Learning}

Self-discipline is the beginning of success. Fragmented learning is after all a form of autonomous learning. In the process of learning, students should take both the learning content and themselves as the object of cognition. They must make an objective and correct self-evaluation, based on which they may conduct self-stimulation, self-control and selfregulation to form a healthy psychological quality, so that their attention, willpower, and ability to resist setbacks will get continuously improved.

At present, with the support of mobile Internet technology, there are numerous ways to acquire information such as MOOC, live broadcast teaching, short video, digital broadcast, game clearance, network news. The learning contents are generally provided by various media in a relaxed and entertaining way. So it is difficult for students to study deeply around a subject if they fall short of the ability to distinguish and control themselves. Thus, it may cause a waste of learning time and deviation of learning aims.

Therefore, fragmented learning highly emphasizes a learner's self-awareness, self-motivation and self-control Learners can study effectively for a long time only when they establish a good sense of self-management and fragmented learning mode by selecting appropriate learning contents with suitable strategies according to their own aims and styles on the basis of strict self-discipline. Once formed, these habits and 
models can help learners to make progress in foreign language learning, and establish lifelong learning habits so as to lay the foundation for their future career development.

\section{CONCLUSION}

In short, fragmented learning is a typical trend in the Internet era, and it is also an important way for college students to acquire knowledge and construct their knowledge system. It will be not only beneficial to improve individual achievement of foreign language learning, but also helpful to explore online and offline mixed teaching mode and improve the overall teaching level of college English by understanding the cognition and preference of higher vocational college students for fragmented foreign language learning and giving them scientific and reasonable guidance and help.

\section{REFERENCES}

[1] Wang Zhuli, New Constructivism: a Learning Theory in Network Era [J], Journal of Distance Education, 2011(02), pp.12-18

[2] Wang Zhuli, New Constructivism: a Learning Theory in Network Era[J], Journal of Distance Education, 2011(05), pp.34-40

[3] Zhu Zhiting, The Latest Developments of Education Informatization: International Observations and Domestic Trends[J], Journal of Distance Education,2012(03), pp.3-13

[4] Huang Ling, Study on Fragmented Learning Habits and Teaching Design of College Students under the Background of Big Data Era [J], China Adult Education, 2016(23), pp.15-17

[5] Wei Xuefeng, Yang Xianmin, Zhang Yumei, Application Scenarios and Efficient Management of Fragmented Learning Resources in Mobile Internet Era [J], China Educational Technology, 2017(05), pp.117-122

[6] Tan Chunlei, Fragmented English learning from the perspective of constructivism [J], Home Drama, 2019(32), pp.148-150 